\title{
LA VIDA DESPUÉS DE LA VIDA. EL CONCEPTO DE "NACHLEBEN" EN BENJAMIN Y WARBURG
}

\author{
AFTERLIFE. THE CONCEPT OF “NACHLEBEN” IN BENJAMIN AND WARBURG
}

\author{
Mariela Silvana Vargas ${ }^{1}$ \\ Technische Universität zu Berlin (Alemania)
}

Recibido: 04-07-2013

Aceptado: 30-11-2013

Resumen: El concepto de "Nachleben" ocupa un lugar central en la reflexión del siglo XIX en alemania, tanto en su vertiente evolucionista como "supervivencia" (survival, Überleben), como en su aspecto vinculado al estudio de la historia de la "pervivencia" (afterlife, Nachleben) de productos culturales. Entendido como "pervivencia" el concepto de "Nachleben" se encuentra presente en la obra de Walter Benjamin y Aby Warburg. Este trabajo indaga el sentido del término en ambos pensadores, su relación con su contexto de surgimiento y las consecuencias para la comprensión de la historia y la naturaleza de los productos culturales.

Palabras-clave: Nachleben, pervivencia, Benjamin, Warburg, historia, cultura.

\begin{abstract}
The concept of "Nachleben" has a central place in the thought of the nineteenth century in Germany in both of its meanings, as survival (Überleben) in an evolutionary perspective and as afterlife (Nachleben) of the cultural products. Understood as afterlife the concept of Nachleben plays a substantial role on the works of Walter Benjamin and Aby Warburg. In this paper I investigate the meaning of the term in both thinkers, it's connections with it's context of origin and the consequences for the understanding of history and of the nature of cultural products.
\end{abstract} Key-words: Nachleben, afterlife, Benjamin, Warburg, history, culture.

[1] (marielasvargas@hotmail.com) Mariela Vargas. Lic. en Filosofía. Becaria doctoral en la Technische Universität zu Berlin. Docente e Investigadora de la Universidad Nacional de Salta y de la Universidad Católica de Salta (Argentina). Fue visiting scholar del Peter Szondi-Institut für Allgemeine und Vergleichende Literaturwissenschaft (2013) y del Zentrum für Literatur- und Kulturforschung Berlin (2014). Publicaciones: Vargas, M. (2012): "El problema del tiempo histórico y la imagen dialéctica en Walter Benjamin" en Revista Latinoamericana de Filosofía, ISSN 0325-0725. Volumen XXXVIII, N¹, pp. 85-108. Traducciones: Vargas, M. y Simesen, M.: Winfried Menninghaus: "Saber de los umbrales. Walter Benjamin y el pasaje del mito". Editorial Biblos, Buenos Aires. $1^{\circ}$ Ed. Octubre de 2013. ISBN 978-987-691-103-0. 


\section{El concepto de "Nachleben" en la historia cultural alemana}

La entrada correspondiente al vocablo "Nachleben" en el diccionario de los hermanos Jacob y Wilhelm Grimm lo define como 1) "nachfolgendes, nachdauerndes leben" [vida posterior, vida que pervive] y 2) "nachahmendes leben" [vida que imita]. ${ }^{2}$ El verbo "nachleben" recoge también el doble significado de sobrevivir e imitar, tomar a alguien como ejemplo. En diccionarios contemporáneos se define "Nachleben" como "la vida de un muerto en el recuerdo de sus deudos" o la "pervivencia en el recuerdo de los descendientes"3 y al verbo "nachleben" como imitar, "vivir de acuerdo al ejemplo dado por alguien". Este último significado vincula "nachleben" con "nacherleben", cuya definición es "revivir a través del recuerdo algo que otros han vivido". El amplio e intrincado campo semántico en el que estos vocablos se encuentran insertos dentro de la lengua alemana, así como su circulación dentro de las distintas áreas del saber, tales como la biología, la filología y la antropología explica en parte por qué se volvieron centrales en la reflexión de comienzos del siglo veinte sobre la relación entre la vida, la memoria colectiva, la historia y la tradición.

El desarrollo de nuevas técnicas filológicas que permitieron la recuperación, edición y puesta en circulación por primera vez de numerosos textos de la antigüedad grecolatina, así como el auge del historicismo impactaron en la consciencia histórica europea e impulsaron la teorización y el debate en torno a la identidad nacional, la historia y la herencia cultural. El nacimiento de la historia del arte como disciplina con el estudio de Winckelmann Historia del arte de la Antigüedad ${ }^{5}$ era sintomático de este desarrollo y preparó el terreno a su vez para el surgimiento de los trabajos de Aby Warburg sobre el renacimiento del paganismo. A pesar del uso más bien discreto que se registra del concepto de Nachleben en los textos de Warburg, si bien en lugares centrales ${ }^{6}$, y precisamente por la ausencia de una tematización explícita de sus implicaciones epistemológicas, éste se convirtió en un reservorio de representaciones a partir de las cuales se pensaba la historia como aquello que sucede con la vida (Leben) de ciertos gestos, imágenes y formas expresivas durante el tiempo que

[2] Jacob y Wilhelm Grimm, Deutsches Wörterbuch, Tomo 7, Leipzig, Hirzel, 1889, Col. 90s.

[3] El Diccionario Duden Online (www.duden.de) lo define como "Leben eines Verstorbenen in der Erinnerung der Hinterbliebenen" y el Wahrig como "Fortleben in der Erinnerung der Nachkommen”. Cf. Wahrig Deutsches Wörterbuch, Bertelsmann Verlag, Munich, 2000, p. 901.

[4] Cf. Entradas "nachleben” y "nacherleben” del Diccionario Duden Online (www.duden.de).

[5] Johann J. Winckelmann, Geschichte der Kunst des Alterthums, Dresde, Walther, 1764. (Edición castellana: Historia del arte en la Antigüedad, Madrid, Aguilar, 1989).

[6] Cf. El análisis que realiza Martin Treml sobre los usos de "Nachleben" en Lessing y Jean Paul, dos autores muy importantes para Aby Warburg. Martin Treml, "Warburgs Nachleben. Ein Gelehrte und (s)eine Denkfigur”, en: Weidner, D; Treml, M. (Ed) Nachleben der Religionen. Kulturwissenschaftliche Untersuchungen zur Dialektik der Säkularisierung, Munich, 2007, pp. 25-40.

THÉMATA. Revista de Filosofía, Nº49 enero-junio (2014) pp.: 317-331

doi: 10.12795/themata.2014.i49.17 
siguió a un acontecimiento, entendido como su acontecer originario, expresado en el sufijo "nach". Pensadores tan disímiles entre sí, tales como Friedrich Nietzsche, Georg Simmel, Sigmund Freud, Wilhelm Dilthey, Aby Warburg y Walter Benjamin, colocaron en el centro de sus intereses la cuestión de la vida propia del pasado y de las manifestaciones culturales y sociales entendidas como dotadas de vida propia. En este trabajo me ocuparé de examinar el contexto de las discusiones en torno al Nachleben en el paisaje de la historia de la cultura alemana y delinearé los usos del concepto en Benjamin y Warburg y sus supuestos compartidos.

\section{Formas de pervivencia entre la biología y la filología}

Estimulada por descubrimientos provenientes de la biología y la filología, las cuales se ocupaban del devenir de textos y de los organismos vivos a lo largo de la historia, la reflexión sobre la vida se había convertido en el umbral del siglo veinte en un tópico presente en los más variados campos del saber. La recepción y la amplia discusión en torno a la teoría de la evolución de Darwin que venía teniendo lugar desde finales del siglo diecinueve tuvo una amplia repercusión en las ciencias humanas y la filosofía. La influencia de este debate se hizo visible, por un lado, en la incorporación de la terminología propia de las ciencias naturales para pensar la historia, la cultura y la sociedad, aunque con matices propios con, los que se pretendía lograr un cierto distanciamiento de las ciencias naturales por parte de las Geisteswissenschaften y, por otro lado, en el creciente interés por una "filosofía de vida" (Lebensphilosophie) y una antropología filosófica, cuya reflexión giraba en torno al concepto de supervivencia. El interés por la temática de la vida se desdobló, por un lado, en la reflexión evolucionista en torno a la "supervivencia" (survival, Überleben) y en el estudio dentro de la historia de los fenómenos de "pervivencia" (afterlife, Nachleben) por el otro. ${ }^{7}$

Entendido de esta manera, es decir, alejado del modelo evolucionista darwinista, el concepto de Nachleben se inscribía dentro de las "ciencias del espíritu" en el marco de un modelo no antropomórfico de la historia de la cultura y que no se orientaba según el ritmo propio de las edades humanas, ni se proyectaba en estadios o etapas de desarrollo, pero que, sin embargo, consideraba que los productos culturales estaban dotados de una vida y una vitalidad propias. El retorno de ciertos elementos luego de su aparente olvido o su circula-

[7] La necesidad de distinguir entre el modelo darwinista de supervivencia, vinculado a las ideas de adaptación y "selección natural" y el modelo de las ciencias de la cultura, que no supone teleología alguna a la hora de pensar la pervivencia de ciertas formas, se muestra en el título del libro de Georges Didi-Huberman "L' image survivant", la cual hace un uso como participio presente del término que traduce "Nachleben". Cf. Didi-Huberman, L' image survivant, Minuit, Paris, 2002 (Ed. Cast. La imagen superviviente, Abada, Madrid, 2009).

THÉMATA. Revista de Filosofía, Nº49 enero-junio (2014) pp.: 317-331

doi: 10.12795/themata.2014.i49.17 
ción encubierta en forma de detalles en imágenes constituyen ejemplos de esta forma de expresión de esta temporalidad y forma de vida de algunos objetos y fuerzas presentes en la cultura. Para Benjamin las citas y referencias tendrían una función similar, pues el mecanismo de la cita intercala algo ajeno en el cuerpo del texto, lo secciona e interrumpe. Aún en su función de ornamento, de embellecimiento de un texto, la cita trasciende de este modo la dimensión de la mera intertextualidad y pone en juego una "intertemporalidad" gracias a la que perviven los textos del pasado.

Por su parte, el desarrollo y el refinamiento de técnicas filológicas de decodificación de textos, que habían conducido al nacimiento de la filología comparada y, en el marco de la filología griega, al monumental trabajo de edición de los fragmentos de los presocráticos llevada a cabo por Hermann Diels y Walther Kranz, generó nuevas herramientas para la comprensión de las culturas del pasado. En particular, el acceso a nuevos textos del mundo grecolatino estimuló una reflexión acerca de la presencia de la antigüedad en la cultura alemana y de la pervivencia de los orígenes de la tradición occidental en manifestaciones culturales contemporáneas. En este sentido, al hablar de Nachleben se está haciendo referencia también a un concepto propio de la filología alemana de los años veinte. Otto Inmisch, filólogo y profesor en la universidad de Freiburg escribe en 1919 en un folleto al que titula Das Nachleben der Antike

Las viejas estrellas brillan nuevamente sobre nosotros. Vemos por este camino que la idea de la unicidad de los fenómenos históricos no es correcta, pues hay renovaciones y renacimientos [Wiederaufleben] que son mucho más que una mera reconstrucción histórica.

El motivo por el que la reconstrucción y descubrimiento de las huellas de la antigüedad no posee un carácter meramente "histórico" es porque "todo lo que alguna vez vivió y obró, continúa vivo y obrando” [,Alles überhaupt, was lebte und wirkte, lebt und wirkt auch weiter"]. Curiosamente, el modelo para pensar la antigüedad griega y latina es el cristianismo, y más precisamente, la figura de Jesús. Inmisch establece una comparación entre el estudio de la antigüedad clásica y la figura de Jesús:

Jesús puede ser entendido de manera histórica en el contexto de su tiempo; sin embargo, a él pertenecen también de modo inseparable el evangelio y la iglesia, así como su pervivencia [Nachleben] total, permanentemente transformada y todavía transformable, hasta el día de hoy no agotada; verdaderamente no se trata de un acontecimiento "único", sino que, visto como un todo, de un enorme y continua fuente de energía. ${ }^{9}$

[8] Cf. Otto Inmisch, Das Nachleben der Antike, Leipzig, Dieterich, 1919, p. 15s: "Die alten Sterne leuchten wieder, auch uns. Wir sehen auch auf diesem Wege, mit der Einmaligkeit der Geschichtlichen Erscheinung stimmt es nicht, es gibt ein Erneuern, ein Wiederaufleben, das viel mehr ist als bloße geschichtliche Rekonstruktion“.

[9] Immisch, Íbid, p. 16s: „Jesus kann historisch im Kontext seiner Zeit verstanden werden, doch gehört untrennbar zu ihm auch das Evangelium und die Kirche, sein ganzes stets gewandeltes, aber noch immer wandelbares und bis auf den heutigen Tag unerschöpftes Nachleben- wahrlich

THÉMATA. Revista de Filosofía, Nº 49 enero-junio (2014) pp.: 317-331

doi: 10.12795/themata.2014.i49.17 
En el enfoque filológico de Immisch se entremezclan y potencian un paradigma teológico basado en la figura de Jesús y uno energético, a partir del cual se piensa la historia de la cultura. Los productos del "espíritu" son "formas acuñadas, que, viviendo, se desarrollan"10 y dan lugar a nuevas configuraciones, pues los contenidos y formas generan permanentemente efectos nuevos y productos intelectuales autónomos. En la expresión "Nachleben der Antike" Immisch condensa sus posiciones en relación al pasado y a la herencia cultural. En la noción de una pervivencia de la antigüedad conviven la idea de que la antigüedad está viva y de que es parte del actual "proceso de la vida", es decir, no se trata de algo lejano y acabado, como lo consideraba la representación tradicional de las épocas pasadas, sino que la exigencia de comprender la antigüedad de esa manera se convierte en la exigencia de encarnar en el presente las formas de aquélla; no sólo de imitarlas, sino de incorporarlas a la vida. Si la idea de un "Nachleben der Antike" se convirtió en un paradigma para las ciencias de la cultura y la filología fue en gran parte debido a la ambigüedad del genitivo der, el cual puede ser entendido tanto como un genitivo objetivo como uno subjetivo. La expresión no deja en claro si se afirma que la antigüedad pervive, es decir, si continúa viviendo, o si nosotros la hacemos vivir, si la revivimos ("nacherleben"). La vida de las formas se refiere, por lo tanto, permanentemente tanto al pasado como al futuro.

En Benjamin y en Warburg se encuentran presentes, si bien con diferente intensidad, ambos aspectos del "Nachleben", tanto el que podría denominarse "objetivo" y que refiere a los contenidos que persisten, perviven y circulan en el espacio cultural, como el que podría denominarse "subjetivo", que apela a la memoria de la posteridad e incita a las nuevas generaciones a imitar y hacer revivir el pasado. En Warburg las imágenes asumen un papel fundamental en la transmisión y en la conceptualización de la supervivencia del pasado. Las Pathosformeln-fórmulas del pathos- poseen por definición una Nachleben, es decir, son capaces de pervivir y sobrevivir el paso del tiempo y son capaces de conservar y transmitir contenidos, formas y emociones puesto que están marcadas "engramáticamente" 11 por las fuerzas del pasado. En su estudio sobre la pintura del Renacimiento, Warburg concentraba su interés en los detalles del ropaje y del movimiento pues estos contienen y transportan

keine „Einmaligkeit“, sondern als ganzes ein zusammenhängender Energieumsatz”.

[10] Immisch, Íbid, p. 16.

[11] El concepto de "Engrama" fue tomado por Warburg de Karl Lashey (1890-1958), quien a su vez lo desarrolló a partir de la noción de "Mneme" de Richard Semon (1859-1918), un biólogo evolucionista alemán, defensor del monismo. En sus intentos de mostrar la base biológica neuronal de la memoria, Lashey postuló la existencia de engramas o patrones de activación formados por estimulaciones internas y externas que recoge el sistema nervioso y que desembocan en el cerebro donde producen patrones de estimulación específicos. Cada uno de estos patrones es un engrama y su función era la de preservar la energía psíquica en la sustancia del cerebro. Cf. Richard Semon, Die Mneme als erhaltendes Prinzip im Wechsel des organischen Geschehens, Leipzig, 1904.

THÉMATA. Revista de Filosofía, Nº49 enero-junio (2014) pp.: 317-331

doi: 10.12795/themata.2014.i49.17 
aquellas energías del pasado. Se trata de una concepción energética y dinámica de la imagen y de la vida de la imagen que subraya el aspecto objetivo de la pervivencia de la antigüedad en el arte del renacimiento.

Esta idea de que un contenido, forma, idea o pathos del pasado, dotado de un valor objetivo y una vida propias incide sobre las producciones artísticas e intelectuales del presente ocupa también en Benjamin un lugar central dentro de sus análisis culturales y de su noción de crítica de arte. Las ideas políticas de Benjamin son subsidiarias asimismo de esta concepción de un pasado que no está ni muerto ni cerrado, en particular, de la idea de un pasado que tendría derechos sobre el presente, una idea que Benjamin condensa en la imagen de la "débil fuerza mesiánica" $(\mathrm{I}, 694)^{12}$ de lo pretérito. Otras veces prevalece el elemento subjetivo del Nachleben, aquél que llama a rescatar objetos y energías de ese pasado que podrían perderse y desaparecer. En ambos autores lo que está en juego en última instancia es la concepción de la historia y de la función del historiador o crítico del arte y la cultura. Ésta consiste en liberar las energías revolucionarias que residen en lo pasado de moda y lo aparentemente olvidado. ${ }^{13}$

\section{Walter Benjamin y el Nachleben de las obras de arte}

Mucho más interesados por las ideas de Benjamin sobre la noción de "origen", que por el concepto de Nachleben, ligado a aquél, los comentaristas descuidaron esta noción importante dentro de su obra. El concepto de Nachleben es particularmente interesante porque permite conectar su pensamiento con el de sus contemporáneos y con una problemática, la de la relación entre vida, historia y memoria, que estaba presente en el paisaje intelectual alemán de la primera mitad del siglo veinte. Desde cierto punto de vista, la filosofía de Benjamin es un intento por pensar la historia y la tradición a partir de los conceptos de Leben y Nachleben y de Vor- y Nachgeschichte. Esta doble perspectiva encuentra una de sus formulaciones más claras en el Origen del drama barroco alemán. Allí Benjamin señala que "el origen, por tanto, no se pone de relieve en el dato fáctico, sino que concierne a su prehistoria y posthistoria" (I, 226). La comprensión de las "líneas directrices" de la contemplación

[12] Walter Benjamin, Gesammelte Schriften, Tomo I, Frankfurt del Meno, Suhrkamp, 1991. Las obras de Benjamin se citan del original alemán de acuerdo a la citación estándar de los Gesammelte Schriften: los números romanos corresponden al número de tomo y las cifras arábigas al número de página. A menos que se indique lo contrario, todas las traducciones son mías. En la tesis II de Sobre el concepto de historia Benjamin sostiene que "existe un secreto acuerdo entre las generaciones pasadas y la nuestra. Entonces hemos sido esperados en la tierra. Entonces nos ha sido dada, tal como a cada generación que nos precedió, una débil fuerza mesiánica, sobre la cual el pasado reclama derecho. No es fácil atender a esta reclamación. El materialista histórico lo sabe" (I, 698). [13] Cf. Irving Wohlfarth, Et Cetera? The Historian as Chiffonnier en: New German Critique, $\mathrm{N}^{\circ}$ 39 (Otoño, 1986), pp. 142-168.

THÉMATA. Revista de Filosofía, Nº49 enero-junio (2014) pp.: 317-331

doi: 10.12795/themata.2014.i49.17 
filosófica del origen en tanto categoría histórica requieren atender a la "dialéctica inherente al origen" (I, 226), consistente en el condicionamiento recíproco de la "unicidad" y la "repetición" propia de los fenómenos. Es en torno a ese movimiento, que Benjamin entiende como genuinamente histórico, que puede construirse un pensamiento de la vida y la supervivencia de las obras de arte y de la prehistoria y la posthistoria para estudiar los fenómenos y los productos de la cultura.

Para Benjamin tanto las obras de arte, como las "formas puras" tienen una vida, que, a raíz de su independencia de la vida humana, él caracteriza como un tipo de "vida natural" (I, 227). Por su despliegue "claro e imperturbado" por la vida humana, la pre- y la posthistoria de las obras no son "historia pura, sino que son historia natural" 14 (I, 227). En La tarea del traductor Benjamin afirma que el original "sobrevive", continúa viviendo en la traducción. Esta compenetración entre historia, obra y vida es expresada en los siguientes términos:

así como las manifestaciones de la vida están íntimamente relacionadas con todo ser vivo, aunque no representan nada para éste, también la traducción brota del original, pero no tanto de su vida como de su "supervivencia», pues la traducción es posterior al original" (IV, 11).

Para Benjamin "la idea de la vida y de la supervivencia de las obras debe entenderse con un rigor totalmente exento de metáforas" (IV, 11). Es precisamente este uso estricto y no metafórico del concepto de vida el que muestra hasta qué punto las ideas de Benjamin estaban embebidas de la terminología de la época. En Benjamin, la reflexión sobre la historia y las obras de arte como seres vivos estaba ligada además al interés epistemológico de fundar una forma de reflexión sin sujeto (ichfreie Reflexion). La defensa de la atribución de una "vida" a las obras literarias y a las formas artísticas supone depurar el concepto de vida de sus referencias al alma o a la sensibilidad animal. Así sostiene Benjamin que:

Ni siquiera en las épocas de mayor confusión mental se ha supuesto que sólo el organismo pudiera estar dotado de vida. Pero ello no es razón para pretender extender el imperio de la vida bajo el frágil cetro del alma, como lo intentó Fechner; ni tampoco para decir que sería posible definir la vida basándose en los actos todavía menos decisivos de la animalidad o en el sentimiento, que sólo la caracteriza ocasionalmente. (IV, 11)

[14] "La idea de historia natural" (1932) es el texto en el que Adorno desarrolló su apropiación de este concepto benjaminiano. Acerca de su perspectiva sobre el mismo, Adorno sostiene que ésta apunta a "la superación de la antítesis habitual entre naturaleza e historia" y aclara que su uso del concepto de naturaleza no tienen que ver con la acepción del mismo en el marco de las "ciencias matemáticas de la naturaleza", sino que guarda una íntima relación con el mito. De hecho, "mito", entendido como "lo que está ahí desde siempre, lo que sustenta a la historia humana y aparece en ella como Ser dado de antemano" sería la "traducción" que más se le aproximaría. Cf. Theodor Adorno, "Die Idee der Naturgeschichte" en Gesammelte Schriften, Tomo I, Philosophische Frühschriften, Frankfurt del Meno, Suhrkamp, 2003, p. 345.

THÉMATA. Revista de Filosofía, Nº49 enero-junio (2014) pp.: 317-331

doi: 10.12795/themata.2014.i49.17 
Esta concepción de la vida, no vinculada de manera esencial a formas humanas o animales de percepción o autoconciencia, se convertirá en un concepto central dentro de las ciencia alemana de la cultura. Dentro del plexo semántico en el que se inscribe el concepto "Nachleben", se encuentran también "Überleben" y "Fortleben", que significan "supervivencia" y "pervivencia" respectivamente, dos términos que traducen también el concepto de "Nachleben" y que si bien aparecen como sinónimos, tienen un matiz semántico diferente. A diferencia de "pervivencia", que es en cierto sentido más neutra, "supervivencia", en tanto que es un concepto básico de la teoría evolucionista de Darwin tiene una carga teórica de la que aquélla carece. Mientras que "supervivencia" implica la superación de algún obstáculo y esfuerzos adaptativos dirigidos a ello y está inmediatamente ligada al "survival of the fittest" y a la lucha por la existencia, "pervivencia" expresa más bien la permanencia de algo con vida, a pesar de que muchas otras cosas hayan cambiado o desaparecido. Lo que pervive tiene una sobre-vida, una vida después de la vida, que se despliega sin luchar necesariamente contra algo que se le opone, sino que posee una suerte de energía y temporalidad propias.

Estas consideraciones sobre la vida de las obras de arte tienen como consecuencia la puesta en cuestión de la historiografía tradicional. En una carta de diciembre de 1923 dirigida a Florens Christian Rang, Benjamin expone brevemente su teoría acerca de la obra de arte y de la inexistencia de la historia del arte como sucesión de estilos. En aquélla carta Benjamin le comenta a su amigo el tema actual de sus reflexiones: el problema de "cómo las obras de arte se relacionan con la vida histórica [geschichtliches Leben]" y sostiene que "no existe la historia del arte" como tal $(2,392) .{ }^{15}$ Benjamin expresa así su rechazo a una metodología de la historia del arte que conciba a ésta como una descripción genealógica de la sucesión de las obras de arte a lo largo de la historia, que señale los nacimientos, las decadencias y muerte de los estilos y se ocupe de establecer relaciones de influencia, parentesco, etc. Lo que diferencia la vida de las personas de las de la obra de arte es que mientras que los seres humanos guardan relaciones de precedencia entre sí, es decir, están inmersos en la lógica de las generaciones, la obra de arte, por el contrario, es "de acuerdo a su esencia ahistórica" $(2,392)$ y no se orienta de acuerdo a los patrones de la vida humana y sus categorías genealógicas y de muerte, decadencia o madurez.

Benjamin critica la narración que propone la historia del arte tradicional porque ella no conduce al núcleo de la obra de la arte: "La investigación actual sobre el arte contemporáneo se reduce a una mera historia de sus materiales o de la forma, para las cuales las obras de arte sólo consisten en ejemplos o, en cierto modo, modelos; no se plantea la cuestión de una historia de

[15] Walter Benjamin, Gesammelte Briefe, 6 Tomos, Frankfurt del Meno, Suhrkamp, 1998. Las cartas de Benjamin se citan de acuerdo al modo de citación estándar: primero se indica el número de tomo y luego el número de página.

THÉMATA. Revista de Filosofía, Nº 49 enero-junio (2014) pp.: 317-331

doi: 10.12795/themata.2014.i49.17 
las obras de arte como tal" $(2,392)$. El vínculo genealógico existente entre las distintas generaciones conecta a los seres humanos es un vínculo "extensivo", mientras que la conexión fundamental entre el paso del tiempo y la obra de arte es "intensiva". En este sentido, "la historicidad específica de las obras de arte es de tal índole [i. e. intensiva] y no se revela en la historia del arte, sino sólo en la interpretación" $(2,392)$. En la interpretación, la crítica y la traducción la vida de la obra de arte entrega su carozo propiamente histórico bajo el manto de la eternidad: "en la interpretación las relaciones entre las obras de arte se presentan como eternas aunque no sin relevancia histórica" $(2,393)$.

\section{Warburg y el Nachleben de las imágenes}

También para Aby Warburg la atención a la particular temporalidad de las obras de arte y a la vida de éstas que se despliega en la historia supone una puesta en cuestión de los fundamentos y los modelos epistémicos de la historia del arte. En este punto llama la atención la manera en que un especialista como Georges Didi-Huberman interpreta el signo y el valor de la práctica historiográfica de Warburg y las herramientas conceptuales que la orientan, pues parece, porque perder de vista el elemento vital presente en la noción de Nachleben como pervivencia y supervivencia de Pathosformel en las imágenes. Didi-Huberman entiende el modelo historiográfico Warburgiano como un

"modelo resueltamente no natural y simbólico, un modelo cultural de la historia en el que los tiempos no se calcaban ya sobre estadios biomórficos sino que se expresaban por estratos, bloques híbridos, rizomas, complejidades específicas, retornos a menudo inesperados y objetivos siempre desbaratados" (Didi-Huberman; 2009: 43s).

Sin embargo, el alejamiento de Warburg -similar al de Benjamin- del paradigma natural de "vida y muerte" y "grandeza y decadencia" de las épocas históricas y de los productos culturales no es equivalente al rechazo de la idea de que éstos poseen una vida. Esta vida es, sin embargo, diferente a la vida humana y a sus ciclos y posee otra conexión con la vida histórica. La historia, la crítica y la historia del arte se encargarían justamente de estudiar las particulares relaciones entre historia y vida específica de los productos culturales.

Como se vio, el modelo de Nachleben de la filología y la teoría de la cultura alemanas era la persona de Jesús, quien precisamente representaba la superación de las edades y ciclos vitales humanos. Todo el esfuerzo de Benjamin por elaborar una teoría de la interpretación de las obras de arte puede resumirse en dos ideas: la de la ausencia de épocas de decadencia ${ }^{16} \mathrm{y}$

[16] Cf. la sentencia programática de Benjamin en el convoluto $\mathrm{N}$ del Libro de los Pasajes: "El pathos de este trabajo: no hay épocas de decadencia. Intentar ver el siglo XIX de un modo tan absolutamente positivo como me esforcé en ver el siglo XVII en el trabajo sobre el drama barroco. No creer que hay épocas de decadencia" (V, 571).

THÉMATA. Revista de Filosofía, Nº 49 enero-junio (2014) pp.: 317-331

doi: 10.12795/themata.2014.i49.17 
la idea de que las obras de arte tienen una vida (in)diferente a la vida humana. Por su parte, concepción de una vida del detalle anima toda la obra de Warburg. Sus tres conceptos fundamentales: Pathosformel, bewegtes Leben y Nachleben contienen una referencia a la vida entendida como movimiento, como transición permanente de la acción a la pasión. Si la vida se expresa en determinadas formas del Pathos, de las pasiones del alma y de la pasión, es porque ella es tanto algo que se padece como algo que mueve el ánimo. El movimiento es para Warburg indicio de vida y lo más propio de ella. La supervivencia y el "vivir-después" al que alude el Nachleben son también rasgos propios de la vida y, sobre todo, de la vida pasada: "un ser del pasado no termina de sobrevivir" (Didi-Huberman; 2009:29).

Un ejemplo de la relación productiva entre el concepto de "Nachleben" y la pre- y la posthistoria de un fenómeno puede verse en la perspectiva que adopta Warburg para estudiar el retrato renacentista. La historia tradicional del arte explica el surgimiento del retrato a partir del creciente antropocentrismo y del progreso en las técnicas artísticas imitativas, las que habrían hecho surgir un nuevo género de imagen llamado retrato. Por el contrario, la ciencia de la cultura de Warburg narra otra historia, acorde a la complejidad de la época: la historia de un entrecruzamiento de la magia pagana y de la antigüedad (en el sentido de una pervivencia de la imago romana, la liturgia del cristianismo medieval (la práctica de las imágenes votivas en forma de bustos de cera), así como los rasgos artísticos y espirituales del Quattrocento.

A pesar de la importancia capital del concepto dentro de la historia warburgiana de la cultura, en los textos publicados de Warburg el concepto aparece en muy pocas ocasiones. La primera referencia se encuentra en la fórmula que condensa la empresa warburgiana: rastrear las huellas del Nachleben der Antike, de la supervivencia de la antigüedad en el mundo del Renacimiento y hasta el presente. El instrumento fundamental para rastrear esta supervivencia de la antigüedad era la biblioteca, que Warburg había canjeado por la renuncia a sus derechos de primogénito a la herencia paterna. La biblioteca estaba concebida como una herramienta de investigación, como una lupa para magnificar al "pequeño dios" escondido en los detalles de las imágenes y una "torre blindada de observación" [Beobachtungs-Panzerturm]. ${ }^{17}$

El Atlas Mnemosyne, ${ }^{18}$ un proyecto inconcluso y tal vez, como el proyectado Libro de los Pasajes de Benjamin, interminable, inconcluible, pretendía

[17] Cf. Aby Warburg, "Vom Arsenal zum Laboratorium" en: Aby Warburg, Werke in einem Band, Frankfurt del Meno, 2010, p. 692.

[18] Cf. Aby Warburg, Atlas Mnemosyne, Akal, Madrid, 2010; Sigrid Weigel: "Zur Archäologie von Aby Warburgs Bilderatlas Mnemosyne”, en: Knut Ebeling/ Stefan Altekamp (Ed.): Die Aktualität des Archäologischen in Wissenschaft, Medien und Künsten, Frankfurt a.M., Fischer, 2004, pp. 185208; Cornelia Zumbusch: Wissenschaft in Bildern, Symbol und dialektisches Bild in Aby Warburgs Mnemosyne-Atlas und Walter Benjamins Passagen-Werk, Berlin, Akademie, 2004.

THÉMATA. Revista de Filosofía, Nº49 enero-junio (2014) pp.: 317-331 doi: 10.12795/themata.2014.i49.17 
ser tanto un método de representación de los resultados de la investigación del Instituto Warburg como un instrumento de investigación sobre el repertorio de las imágenes constitutivas de la memoria social y emocional de Occidente. La ninfa extática, a la que Warburg le había dedicado su tesis doctoral, y el dios melancólico fluvial eran los dos polos que estructuraban el mapa de la vida de las imágenes occidentales que Warburg pretendía trazar en su Atlas. Warburg denominó a estas figuras pervivientes Pathosformeln: conglomerados de formas representativas cargados de la vida de las emociones. La disposición de cada imagen dentro del Atlas y sus relaciones con las otras no sólo no eran casuales, sino que sólo afloraban y se volvían perceptibles mediante los cambios de posición, las cercanías y contrastes con las otras imágenes. El objetivo, como lo indica el título que lleva en el anexo de las Obras Completas de Warburg, era captar la "vida en movimiento" [bewegtes Leben]: "Mnemosyne- eine Bilderreihe zur Untersuchung der Funktion vorgeprägter antiker Ausdruckswerte bei der Darstellung bewegten Lebens in der Kunst der europäischen Renaissance". ${ }^{19}$ Una posible traducción sería: Mnemosyne - una serie de imágenes para la investigación de la función de valores de expresión acuñados de la antigüedad para la representación de la vida en movimiento en el arte del renacimiento europeo". La ninfa extática es el ejemplo paradigmático de la "bewegtes Leben", pues expresa no sólo vitalidad y movimiento, sino también conmoción, emoción, es decir, es una fórmula que circula y pervive en la historia para expresar el movimiento en que consiste toda vida, una vida conmovida y la conmoción de la vida a la vez.

En los Gesammelte Schriften la palabra aparece sólo una vez, en "Arte italiano y astrología internacional en el Palazzo Schifanoia de Ferrara" (1912) y en un pasaje en el que el Nachleben, la pervivencia, es contrapuesta a la influencia, la que sería mucho más específica y localizable. Lo que Warburg entiende en principio como obra de la influencia de la antigüedad sobre la pintura renacentista, expresada en el movimiento enfático de cuerpos y ropajes se revela más tarde como producto de la pervivencia y circulación de determinadas Pathosformeln:

Hace aproximadamente veinticuatro años, estando en Florencia, comprendí que la influencia de la Antigüedad en la pintura profana del Quattrocento -sobre todo en el caso de Boticelli y Filippino Lippi- se manifestó en la estilización de los modelos humanos a través de la acentuación del movimiento del cuerpo y los ropajes siguiendo los modelos que se encontraban en las artes plásticas y en la poesía antigua. Más tarde comprendí que los verdaderos extremos de ese lenguaje gestual se hallaban también presentes en la retórica muscular de Pollaiuolo y, sobre todo, que incluso el paganizante universo fabuloso del joven Durero (desde la Muerte de Orfeo hasta los Grandes celos) debía la violencia dramática de su expresión a la pervivencia [nachlebenden] de "fórmulas del pathos" de procedencia

[19] Fritz Saxl, "Anlage der Gesamtausgabe”, en: Aby Warburg, Die Erneuerung der heidnischen Antike. Kulturwissenschaftliche Beiträge zur Geschichte der europäischen Renaissance, editado por Horst Bredekamp/Michael Diers, 2 Tomos, Berlin, Akademie, 1998, p. v.

THÉMATA. Revista de Filosofía, Nº49 enero-junio (2014) pp.: 317-331

doi: 10.12795/themata.2014.i49.17 
griega, que le habían sido transmitidas a través del norte de Italia. (Warburg; 2005: 415 trad. ligeramente modif. La cursiva es mía ${ }^{20}$

Por el contrario, el concepto de Nachleben puebla copiosamente las notas, diarios, cartas y manuscritos no publicados de Warburg. Por ejemplo, en la introducción al Atlas Mnemosyne, donde Warburg se refiere a los "achlebenden monströsen Symbole der hellenistischen Astrologie"21, o bien en los bocetos para "El ritual de la serpiente", en los que Warburg añadió un subtítulo, que si bien no pasó a la versión definitiva es informativo en relación a la concepción de su trabajo sobre el ritual: Das Nachleben primitiven Menschentums in der Kultur der Pueblo Indianer ${ }^{22}$ (La pervivencia de la humanidad primitiva en la cultura de los Indios Pueblo).

El concepto de Nachleben reúne en Warburg al menos tres significados: influencia, pervivencia y supervivencia. En cada momento de la teorización y el trabajo con estos conceptos se producen desplazamientos, superposiciones, rupturas, es decir, movimiento como indicio de la vida del pensamiento y de las obras. Y en cada caso, conceptos como "Leibhaftigkeit" y "Lebendigkeit", que refieren a lo corporal y lo vital son parte de la determinación del concepto de Nachleben (Cf. Treml; 2007: 38). Para Warburg, las obras de arte no pueden ser consideradas solamente como un "producto del atelier del artista", sino que sólo en su "imbricación con los factores contemporáneos de la vida real [wirkliches Leben], pueden reconocerse desde el punto de vista de la historia de los estilos" (Warburg; 2010:691). Es decir, la vida que habita la obra es lo que verdaderamente cuenta a la hora de pensar cuestiones de estilo, con lo que se supedita la historia del arte y la estética a las consideraciones sobre la pervivencia de las Pathosformeln.

\section{Una historia espectral}

Tanto en Benjamin como en Warburg, la concepción de las obras de arte como formas de vida y como objetos capaces de transmitir contenidos cargados a su vez de vitalidad es algo que modifica la relación de éstas con la historia.

[20] Aby Warburg, "Italienische Kunst und internationale Astrologie im Palazzo Schifanoja zu Ferrara" en: Aby Werke, Werke in einem Band, Frankfurt del Meno, 2010, p. 373.

[21] Aby Warburg, "Einleitung", en: Warburg, "Mnemosyne”. Materialien; editado por Werner Rappl, Gudrun Swoboda, Wolfram Pichler y Marianne Koos, München, Dölling und Galitz Verlag, 2005, pp. 11-71. Aquí p. 49s.

[22] Aby Warburg, "Entwurf zum Kreuzlinger Vortrag, 21. April 1923", manuscrito del Warburg Institute London, III.93.4. En otros escritos Warburg hace referencia a un "Nachleben der Triumphalplastik im frühesten Mittelalter" en el manuscrito de la conferencia dictada en el Kunsthistorischen Institut Florenz el 20 de Abril de 1914 titulada "Der Eintritt des antiken Idealstils in die Malerei der Frührenaissance”. Cf. Manuscrito del Warburg Institute London, III.88.1. Ambos citados según Treml; 2007: 39.

THÉMATA. Revista de Filosofía, Nº49 enero-junio (2014) pp.: 317-331

doi: 10.12795/themata.2014.i49.17 
Altera no sólo la historia del arte y la cultura, sino también de la historia en general, en tanto ella está hecha por los seres humanos. El pensamiento de estos autores conduce a una revisión de los fundamentos mismos de la historia del arte y la cultura tradicionales e inaugura una forma de historia de carácter espectral. Donde los "muertos" (corrientes, estilos, tendencias, prácticas, símbolos, significados) no mueren del todo, sino que sólo asumen otras formas de vida, parasitan, enriquecen, contaminan las formas de expresión de las nuevas generaciones. Por este motivo Didi-Huberman sostiene que la historia y el discurso histórico no "nacen" nunca, sino que siempre vuelven a comenzar. Cada vez que su objeto es dado por muerto, se empieza a entrever y reconocer su renacimiento. La historia es eso que tiene lugar, también como disciplina, entre lo muerto y renaciente a la vez (Didi-Huberman; 2009: 29).

El carácter espectral de esta historia consiste en que eso que pervive o que vuelve desde épocas remotas no está bajo control de los sujetos que lo experimentan o reconocen. Para Aby Warburg el "Nachleben" es algo así como un remolino en la corriente del río de la historia y no algo que es meramente arrastrado por su corriente. La supervivencia de un motivo o un ornamento cobran la forma de un fantasma y síntoma -Phantom y Symptom-, son corte e irrupción de tiempos heterogéneos y lejanos en el tiempo del presente. En términos de Ernst Bloch, se trata de un momento de asimultaneidad de lo simultáneo (Ungleichzeitigkeit des Gleichzeitigen). Benjamin por su parte piensa la categoría del origen como una categoría histórica y no lógica, como un "remolino" en medio del río del devenir.

Esta imagen del remolino en el río del devenir es utilizada también por Benjamin en el Origen del drama barroco alemán para definir la noción de origen, el que no es pensado ya como comienzo, sino como novedad que se conforma por el encuentro en torno a un fenómeno con su pre- y la posthistoria. $\mathrm{El}$ "ritmo" de lo originario "se revela solamente a un enfoque doble que lo reconoce como restauración, como rehabilitación, por un lado y justamente debido a ello, como algo imperfecto e inconcluso, por otro" (I, 226) En ese movimiento por el cual la historia se turba y llega a un origen es el movimiento de la vida no humana de las formas, las obras y las imágenes.

Lo propio del torbellino del Nachleben en la historia es que rompe con el juego genealógico de las apropiaciones, de las autorías, del antropocentrismo intrínseco a la historia de la cultura. Como señala Agamben a propósito de Benjamin, "la vida de las imágenes no consiste en la simple inmovilidad ni en la sucesiva recuperación del movimiento, sino en la pausa cargada de tensiones entre ambas" (Agamben; 2010:30). Esa "tensión" es lo que logra su expresión en las fórmulas del pathos warburgianas. Otro aspecto importante de las teorías de estos pensadores es que la energía vital de lo que circula en las obras y la historia, los contenidos que habitan las imágenes no se hallan en posesión de "sujetos" capaces de dar razón de ellos. Se los descubre siempre después, de 
manera retroactiva, a través de la discontinuidad y la intermitencia propia de la vida de las obras. Ellas albergan una experiencia no humana de la vida, pero vinculada a ella. Precisamente gracias a aquello que la vida humana tiene en común con la vida histórica es posible el encuentro con la obra de arte. 


\section{Referencias bibliográficas:}

Adorno, Theodor (2003) "Die Idee der Naturgeschichte" en Gesammelte Schriften, Tomo I, Philosophische Frühschriften, Frankfurt del Meno, Suhrkamp.

Agamben, Giorgio (2010), Ninfas, Valencia, Pre-Textos.

Benjamin, Walter (1991) Gesammelte Schriften, 14 Tomos, Frankfurt del Meno, Suhrkamp.

Benjamin, Walter (2000) Gesammelte Briefe, 6 tomos, Frankfurt del Meno, Suhrkamp.

Burucúa, José E. (2003) Historia, Arte, Cultura De Aby Warburg A Carlo Ginzburg, Buenos Aires, Fondo de Cultura Económica.

Didi-Huberman, Georges (2009) La imagen superviviente. Historia del arte y tiempo de los fantasmas según Aby Warburg, Abada, Madrid.

Benjamin, Walter (2005) Ante el tiempo, Buenos Aires, Adriana Hidalgo editora. Ebeling, Knut / Altekamp, Stefan (Ed.) (2004) Die Aktualität des Archäologischen in Wissenschaft, Medien und Künsten, Frankfurt a.M., Fischer, pp. 185-208.

Grimm, Jacob; Grimm, Wilhelm (1889) Deutsches Wörterbuch, Tomo 7, Leipzig, Hirzel. Inmisch, Otto (1919) Das Nachleben der Antike, Leipzig, Dieterich.

Saxl, Fritz (1998) "Anlage der Gesamtausgabe", en: Aby Warburg, Die Erneuerung der heidnischen Antike. Kulturwissenschaftliche Beiträge zur Geschichte der europäischen Renaissance, editado por Horst Bredekamp/Michael Diers, 2 Tomos, Berlin, Akademie.

Semon, Richard (1904) Die Mneme als erhaltendes Prinzip im Wechsel des organischen Geschehens, Leipzig.

Treml, Martin (2007) "Warburgs Nachleben. Ein Gelehrte und (s)eine Denkfigur”, en: WEIDNER, D; Treml, M. (Ed) Nachleben der Religionen. Kulturwissenschaftliche Untersuchungen zur Dialektik der Säkularisierung, Munich, pp. 25-40.

Warburg, Aby (2005) El renacimiento del paganismo. Aportaciones ala historia cultural del Renacimiento europeo, Madrid, Alianza Editorial.

Warburg, Aby (2010) Atlas Mnemosyne, Akal, Madrid

Warburg, Aby (2010) Werke in einem Band, Frankfurt del Meno, Suhrkamp.

Weigel, Sigrid, (2004) «Zur Archäologie von Aby Warburgs Bilderatlas Mnemosyne». En: Ebeling, K.; Alterkamp, S. (Ed): Die Aktualität des Archäologischen in Wissenschaft, Medien und Künsten. Frankfurt a. M. , pp. 185-208.

Winckelmann, Johann J. (1764) Geschichte der Kunst des Alterthums, Dresde, Walther.

Zumbusch, Cornelia (2004) Wissenschaft in Bildern, Symbol und dialektisches Bild in Aby Warburgs Mnemosyne-Atlas und Walter Benjamins Passagen-Werk, Berlin, Akademie. 
